\title{
The relation of correct and error responses in a serial choice reaction task
}

\author{
DAVID HALE, Applied Psychology Department, University of \\ Aston in Birmingham, England.
}

Error and correct response times were calculated for a serial choice task with two, four, and eight alternatives over five sessions practice. Error RTs were faster than corresponding correct RTs and varied in the same way as the correct RTs with different numbers of alternatives and degree of practice. Error $R T$ were analyzed in detail according to sequential transitions. Eighty-five per cent of errors directly following errors were attempts at error correction. These results are discussed in terms of serial classification and statistical decision models.

Errors in choice-reaction tasks are not necessarily the nuisance they are normally taken to be because they can offer a crucial test of the adequacy of any model for reaction processes. The serial classification model (Hick, 1952; Welford, 1960; Bertelson, 1963) predicts that errors will be faster than the corresponding correct responses because, on the model, the series of classification steps is terminated early and a fast random choice made between the remaining alternatives. Statistical decision models (Stone, 1960; Fitts, 1966; Laming, 1968) predict that errors will be similar to correct responses. Only Fitts' (1966) data support this latter model; other workers (Rabbitt, 1966; Egeth \& Smith, 1967; Schouten \& Bekker, 1967) find errors faster than correct responses. A detailed summary of these models is given by Smith (1968). Both of these models only make predictions for overall RT anyway and cannot handle the specific sequential effects shown by Bertelson (1961), Hale (1967), and Kornblum (1967). The data analyzed here were collected for another purpose when only the correct responses were analyzed.

\section{METHOD}

Three groups of five Ss keyed 1000 responses a session in five sequences of 200 for five sessions. A group worked with either two, four, or eight choice sequences. Stimuli were digits 1 and $2,1-4$, or $1-8$ on an electronic number tube and responses were the directly corresponding keypresses on an add-list keyboard. Another stimulus followed any response after a delay of $100 \mathrm{msec}$ during which time the number tube was blank and Ss could not correct their errors. Stimulus sequences were preprogrammed and read from paper tape for computer analysis. Ss were paid 5s. Od. per 1000 responses and worked under the usual conflicting instructions to maximize speed and minimize errors. RESULTS

The middle 184 responses of each sequence were used in the analysis. Fig. 1 shows the reduction in mean correct and error RT over the five sessions. Error RTs are always faster than the corresponding correct RTs yet are subject to the same variables as affect the correct RT, i.e., practice and choice level. Table 1 analyzes error RTs into different classes of errors according to the type of sequence in which they occur. A repeat error is made when the previous response is repeated when a new response is required. The opposite to this is a premature alternation when a new response is made when the previous response should have been repeated. These are obviously the only two classes of sequential error present in the two-choice sequences. In the multi-choice sequences incorrect alternations can be made when a new but incorrect response is made when a new response is required. Finally, errors following errors are removed as a special class. This was

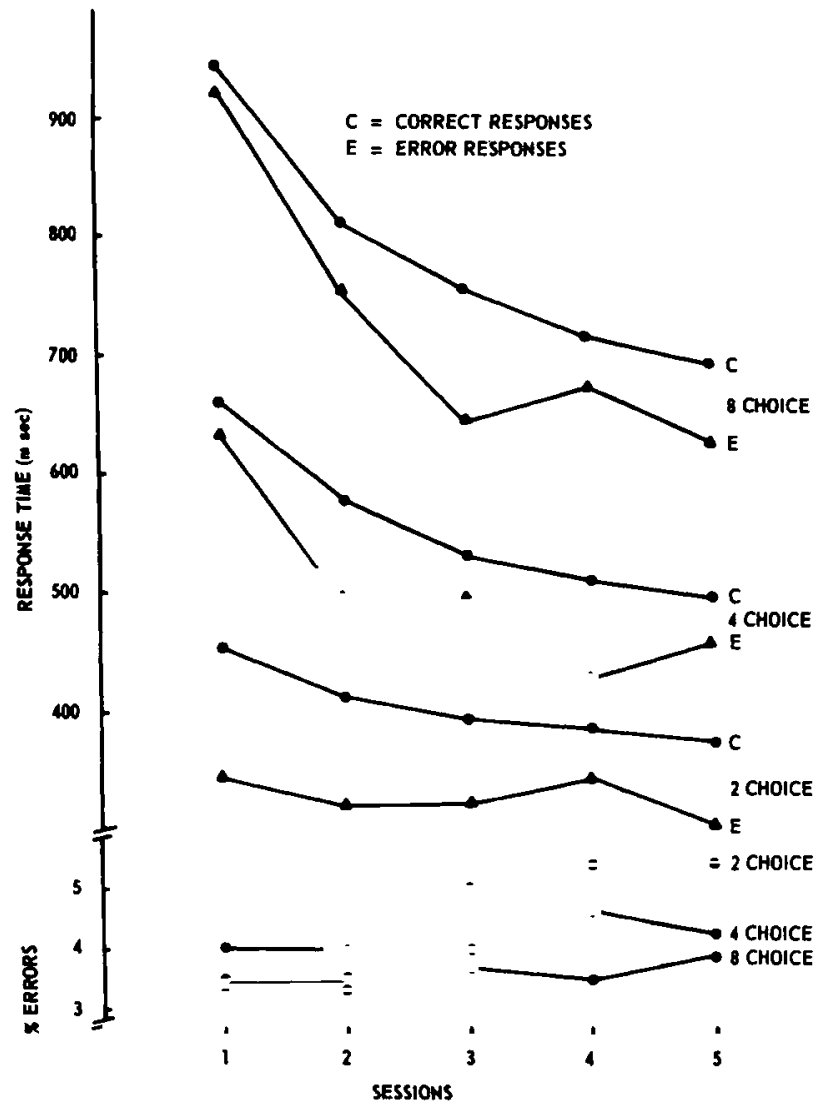

Fig. 1. Mean correct and incorrect RTs for three choice levels over five sessions practice.

justified by the fact that $85 \%$ of these were attempts at illegal error correction.

\section{DISCUSSION}

These results are contrary to a statistical decision model because the errors are consistently faster than the correct responses. Only Fitts (1966) has obtained different results and he used a task with a complex system of payoffs and criterion times. Laming (1968) has suggested a modification of this model which assumes that $S$ s begin sampling information from the display before the next stimulus appears. This would give faster errors but also produces a situation of such complexity that existing statistical decision models cannot really handle quantitatively. The serial classification model receives support here, but again the model is relatively undeveloped to the stage where it can predict the quantitative relationship between

Table 1

Error Response Time for Different Sequential Classes of Errors for 2,4 , and 8 Choice Tasks

\begin{tabular}{lccc}
\hline & 2 Choice & 4 Choice & 8 Choice \\
\hline Correct & 370 & 499 & 698 \\
All errors & 305 & 460 & 627 \\
Repeat errors & 285 & 430 & 470 \\
Incorrect alternations & - & 470 & 650 \\
Premature alternations & 330 & 420 & 520 \\
Error following error & 380 & 435 & 695
\end{tabular}


error and correct RT. Additionally, neither model can as yet begin to handle the detailed differences among error RT. The data confirm the results of Lgeth \& Smith (1967) but in an information "conservation" rather than "reduction" task as they used.

\section{REFERENCES}

BERTELSON, P. Sequential redundancy and speed in a serial two-choice responding task. Quarterly Journal of Experimental Psychology, 1961, $13,90-102$.

BERTELSON, P. S-R relationships and reaction times to new versus repeated signals in a serial task. Journal of Experimental Psychology, $1963,65,478-484$.

EGETH, H., \& SMITH. E. E. On the nature of errors in a choice reaction task. Psychonomic Science, 1967, 8, 345-346.

FITTS, P. M. Cognitive aspects of information processing: III. Set for speed vs accuracy. Journal of Experimental Psychology, 1966, 71, 849-857.

HALE, D. J. Sequential effects in a two-choice serial reaction task. Quarterly Journal of Experimental Psychology, 1967, 19, 133-141.
HICK, W. E. On the rate of gain of information. Quarterly Journal of Experimental Psychology, 1952, 4, 11-26.

KORNBLUM, S. Choice reaction time as a function of conditional probabilities-a re-examination of the information hypothesis. Acta Psychologica, 1967.

LAMING, D. R. J. Information theory of choice reaction times. London: Academic Press, 1968.

RABBITT, P. M. Errors and error correction in choice-response tasks. Journal of Experimental Psychology, 1966, 71, 264-272.

SCHOUTEN, J. F., \& BEKKER, J. A. M. Reaction time and accuracy Acta Psychologica, 1967, 27, 143-153.

SMITH, E. E. Choice reaction time: An analysis of the major theoretical positions. Psychological Bulletin, 1968, 69, 77-110.

STONE, M. Models for choice reaction time. Psychometrika, 1960, 25 251-260.

WELFORD, A. T. The measuremert of sensory-motor performance: Survey and reappraisal of twelve years' progress. Ergonomics, 1960, 3 189-229.

NOTE

1. This research was supported by a Science Research Council contract "On the Acquisition of High Speed Sk ills." 